\title{
Factors associated with Delayed Diagnosis of women Breast Cancer
}

\author{
Nada Salim Hussein ${ }^{1}$, Amal Mohamed Ahmed ${ }^{2}$, Hend Elham Mohamed ${ }^{3}$
}

1. Clinical instructor of Medical Surgical Nursing, Faculty of Nursing - Aswan University

2. Professor of Medical Surgical Nursing, Faculty of Nursing - Aswan University

3. Assistant prof of Medical Surgical Nursing,Faculty of Nursing -Minia University

\begin{abstract}
:
Background: Breast cancer is the most common type of cancer in Egyptian women and although incidence rates are not as high as in the west, yet breast cancer mortality is considerably worse. The nurse plays a critical role in the early detection and prevention of breast cancer. Aim of the study: To assess factors associated with delayed diagnosis of woman breast cancer. Research design: A descriptive exploratory research design. Sample: Purposive sample of 100 women diagnosed with late-stage of breast cancer. Setting: The study was carried out in the surgical inpatient ward and outpatient clinic, chemotherapy and radiation inpatient therapy wards at Aswan oncology cancer institute. Tools of data collection: Structured interview sheet developed by researchers and had two tools, First Tool: covered 2 parts: 1st part: Sociodemographic characteristics; 2nd part: Medical history, Second Tool covered by 2 parts 1st part Knowledge about risk factor and screening test of breast cancer.: 2nd part factors related to women and health care system delay. Study Duration: During the period of four months from the beginning of February 2018 to the end of Mai 2018. Results: The study results revealed that the most common factors that delay diagnosis of breast cancer were lack of awareness of breast cancer (95\%), fear of disease \& treatment adverse effects (53\%). Also, statistically a highly significant $(\mathrm{P}<0.000)$ was found between the level of education with delay diagnosis with a high percentage in illiterate patients delay more than 6 months (92.1\%).Conclusion: Delay in breast cancer diagnosis was influenced by interactions between many factors as lack of awareness about disease and methods of early detection, fear of disease $\&$ treatment adverse effects, and long-distance to a health care center. Recommendations: Educational program is needed to increase females' awareness and knowledge about disease and screening test of early detection.
\end{abstract}

Keywords: Breast Cancer, Educational program, System delay, Women delay.

\section{Introduction}

'Breast cancer' is a malignant tumor that has developed from cells of the breast which affects mostly women, in 2020, approximately one new case diagnosed with breast cancer every 18 seconds; counting for 2.1 million women; whereas the estimated deaths were 626,679 (WHO, 2020)

Breast cancer is the most common type of cancer in Egyptian women and although incidence rates are not as high as in the west yet, breast cancer mortality is considerably worse (Fitzmaurice.,et al,2019). Breast cancer in Egypt constitutes $33 \%$ of female cancer cases and more than 22,000 new cases diagnosed each year (Ahmed.,et al,2020).

Delayed diagnosis of the breast cancer lead to advanced stage presentation and poor clinical outcomes and have low survival rates and has been classified in two types: (1) patient delay, the interval between the discovery of symptoms and the first medical consultation; and (2) system delay, the interval between first consultation and definite diagnosis or treatment. Prolonged delays are usually defined as intervals greater than 12 week (McCutchan,et al,2015).

According to recent studies, factors related to patient delay include( not attributed the symptoms to cancer, patients' distrust, fear of cancer, educational level, supports from family members and friends, financial constraints, ...) . Factors associated with system delay include( factors associated with physician's experience (i.e. medical negligence), mammography misinterpreted, non-specific medical treatment without control, a negative fine-needle aspiration biopsy, surgical excision without pathological examination, not oriented to specialized service, lack of information and appointment delay ...)( Kantelhardt,et al.2015) .

$P$ a g e $\mid 59$
Nurses play vital role in prevention of breast cancer by using their teaching and counseling skills to encourage participation in breast cancer prevention programs and informing patients about recommended screening tests for early detection of breast cancer (Salwa,et al,2015).

\section{Significance of the Study}

Delayed diagnosis of breast cancer is more responsible rather than the disease itself in causing high incidence and mortality rates, leaving a large low of survival (Fitzmaurice.,et al,2019). One of these studies is that conducted at Cairo University Hospital by (Gehan M.et al,2013) and found that the most common factors for delayed diagnosis of breast cancer were lack of awareness about breast cancer and screening test and fear of cancer. In addition, this study is considered the first one in this geographical location to investigate causes and factors associated with Delayed Diagnosis of women Breast Cancer.

\footnotetext{
Aims of the Study

The aim of the study is to assess factors associated with delayed diagnosis of woman breast cancer.

\section{Research question}

1. What are factor associated with delayed diagnosis of woman breast cancer?

2. What are relation between socio-demographic characteristics and factors that delay diagnosis of woman breast cancer?
} 


\section{Subjects and Methods}

Research Design: this study.

A descriptive exploratory research design is used in

\section{Subjects (Sample):}

Purposive sample of 100 women admitted at Aswan oncology cancer institute with diagnosis of late stage of breast cancer.

sample size $\mathrm{n}$ :

This calculator utilizes the following formula for the Where,

$$
\mathrm{n}=\mathrm{N}^{*} \mathrm{X} /(\mathrm{X}+\mathrm{N}-1),
$$

$$
\mathrm{X}=\mathrm{Z}_{\alpha / 2}^{2} * \mathrm{p} *(1-\mathrm{p}) / \mathrm{MOE}^{2},
$$

and $Z_{\alpha / 2}$ is "the critical value of the Normal distribution at $\alpha / 2$ (e.g. for a confidence level of $95 \%, \alpha$ is 0.05 and the critical value is 1.96)", MOE is the margin of error, $\mathrm{p}$ is the sample proportion, and $\mathrm{N}$ is the population size. Note that "a Finite Population Correction has been applied to the sample size formula" $(\mathbf{n}=\mathbf{1 0 0})$.

\section{Inclusion Criteria:}

- All adult female aged between 18 - 65 years.

- Participants were recruited after a definite diagnosis for late stage breast cancer.

\section{Exclusion Criteria:}

- Women who were refused to participate in the study.

- Women who was diagnosed with early stage of breast cancer.

\section{Setting:}

This study was conducted in the surgical inpatient ward and outpatient clinic, chemotherapy and radiation inpatient therapy wards at Aswan oncology cancer institute.

\section{Study duration:}

This study was conducted at Aswan oncology cancer institute during the period of four months from the beginning of February 2018 to end of Mai 2018.

\section{Study Tools:}

Two tools were being constructed and used for collecting data, These tools were formulated by the researcher after extensive review literature(Caplan L,2014 : Maghous‘et al,2016: Gehan,et al,2013 ).

First tool: Bio Socio demographic questionnaire sheet include two parts:

- $\quad \mathbf{1}^{\text {st }}$ part: - socio-demographic data for patients: It consists of (6) item as age, marital status, level of education, occupation, income and residence.

- $\quad 2^{\text {nd }}$ part: - medical data includes family history of breast cancer, presented symptoms, classification of disease and delayed time of diagnosis.

The second tool: which include two parts: Part one: It has two components:

A) Women's knowledge about the screening method of breast cancer and consists of (9) question (4 question about breast self-examination, 3 question about mammogram, 2 question about clinical breast examination).
Scoring system: The total score is 45 grad, score of (5) given for correct answer and score of (0) for incorrect answer.

B) Women's knowledge about the risk factor of breast cancer and consist of (14) item such as their knowledge about (Therapeutic radiation to the chest, A previous benign tumor in the breast, oral contraceptive pills, Hormone replacement therapy,$\ldots \ldots \ldots \ldots . . .$.$) .$

Scoring system: The total score is 75 grade, score of (5) given for correct answer and score of (0) for incorrect answer.

Part 2: It is include two component, factors related to patients delay of breast cancer and consists of (10) item and factor related to health system delay of breast cancer and consists of (8) item.

\section{Tools Validity and reliability}

The tools were tested for content validity by assent of five experts from the faculty of nursing (a jury of five expert's opinion). Tools reliability was done to identify the extent of tools items were measurable with the study concept and its correlation with each other. The reliability of self-care compliance scale was Cronbach's $\alpha=.79$, the content validity coefficient (CVI) of all the items was 0.9.

\section{Pilot study:}

A pilot study was conducted on $10 \%$ (10) of patients to examine the feasibility of the study.

\section{Ethical consideration}

The study was approved by the Research Ethics Committee of the Faculty of Nursing, Minia University. An oral permission was be obtained from patients, the nature and purpose of the study was be explained, patients had right to withdraw from the study at any point . They also informed that the information obtained would be confidential and would be used only for the purpose of the study and their names would be coded for data entry so that their names could not be identified.

\section{Study Procedure}

All participants were recruited after definite diagnosed with late- stage breast cancer at Aswan Oncology Institute, collecting data was done through three days per week from 10 am to $1 \mathrm{pm}$, interviews the sample was taken 45 to 50 minutes to each. The researcher read and explained every item to females and was used an interview questionnaire sheet to collect data through (First tool) and (Second tool).

\section{Limitation of the study:}

Lack awareness and poor understanding of women lead to increase session time.

\section{Statistical analysis:}

Date entry and data analysis were done using SPSS version 24(Statistical Package for Social Science). Data were presented as number, percentage, mean, standard deviation. Chi-square test and Fisher Exact test was used to compare qualitative variables. An independent sample t-test was used to compare quantitative variables between groups. P-value considered statistically significant when $\mathrm{P}<0.05$. 
Minia Scientific Nursing Journal (Print - ISSN 2537-012X) (Online - ISSN 2785-9797) Vol. (9) No. (1) June 2021

\section{Results and data analysis}

Table (1): Percentage distribution of study sample according to their socio- demographic characteristics $(n=100)$.

\begin{tabular}{|c|l|l|}
\hline Item 1- & No. & \% \\
\hline Age "years" & 12 & \\
18-29yrs. & 25 & 12.0 \\
40-39yrs. & 32 & 25.0 \\
50-65yrs. & 31 & 32.0 \\
Mean \pm SD & $46.23 \pm 7.89$ & 31.0 \\
2-Residence: & 33 & \\
Urban & 67 & 33.0 \\
Rural & 19 & 67.0 \\
3-Marital status: & 56 & 19.0 \\
Single & 20 & 56.0 \\
Married & 5 & 20.0 \\
Widowed & 7 & 5.0 \\
Divorce & 25 & \\
Student & 68 & 2.0 \\
Employed & & 68.0 \\
House wife & 70 & \\
4-Occupation: & 12 \\
Illiterate & 10 & 12.0 \\
Primary & 8 & 10.0 \\
Secondary & & 8.0 \\
Higher educational & 57 & 57.0 \\
5-Level of education: & 43 & 43.0 \\
\hline Low & & \\
High & & \\
6- Monthly income: & & \\
\hline
\end{tabular}

Table (1) showed that more than one-third of women (37.0\%) are ranged from $18<40$ years old, with mean age, $46.23 \pm 7.89$ years, about residence it was found that $(67.0 \%)$ of patients from Rural, regarding occupation there was $(68.0 \%)$ housewife .on other hands more than half of the study $(56.0 \%)$ was married, also there was $(70.0 \%)$ of patients illiterate. According to income, it was found that more than half of patients with low income and highest percentage were $(57.0 \%)$.

Table (2): Mean distribution of study sample according to the delayed time $(n=100)$.

\begin{tabular}{|l|l|}
\hline Item & Descriptive "n=100" \\
\hline 1-Time of appearance of symptoms "months" & 1 r.45 2.38 \\
\hline 2-Time of first consultation “months" & $8.72 \pm 1.50$ \\
\hline 3-Time of first diagnosis "months" & $6.21 \pm 1.08$ \\
\hline 4-Time of beginning of treatment & $3.48 \pm 1.74$ \\
\hline 5-Total time delay & $15.43 \pm 4.15$ \\
\hline
\end{tabular}

Table (2) showed the mean distribution of the study sample according to the delayed time, the total time delay was 15.43 months.

Table (3): Percentage distribution of study sample according to factors that delay women in diagnosis of breast cancer $(\mathbf{n}=\mathbf{1 0 0})$.

\begin{tabular}{|l|l|l|l|}
\hline \multirow{2}{*}{ Item } & Yes & No \\
\cline { 2 - 4 } & No. & \% & No. \\
\hline 1-Lack awareness of breast cancer and signs \&symptoms & 95 & 95.0 & 5 \\
\hline 2-Fear of disease \& treatment adverse effects & 53 & 53.0 & 47 \\
\hline 3-No support from family \& friends & 3 & 3.0 & 97 \\
\hline 4-Use of traditional methods & 4 & 4.0 & 96 \\
\hline 5-Financial constraints & 16 & 16.0 & 84 \\
\hline 6-Embarrassment about having a breast ex. & 5 & 5.0 & 95 \\
\hline $\begin{array}{l}\text { 7-Not acceptance of hospital treatment or distrust in success of therapy \& } \\
\text { medical system }\end{array}$ & 12 & 96.0 \\
\hline 8-Fear of social isolation \& sanctions by relatives & 9 & 84.0 \\
\hline 9-Strong religious beliefs & 10 & 95.0 \\
\hline 10-Competing life priorities & 8 & 10.0 & 88 \\
\hline
\end{tabular}

Table (3) showed that the majority of a patient (96\%) had Lack awareness of breast cancer and signs \&symptoms, about $(53 \%)$ had fear of disease \& treatment adverse effects.

Table (4): Percentage distribution of study sample according to relation between socio- demographic characteristics \& delay diagnosis.

\begin{tabular}{|c|c|c|c|c|c|}
\hline \multirow{2}{*}{ Item } & \multicolumn{2}{|c|}{$<6$ mons. "n=24" } & \multicolumn{2}{|c|}{$>6$ mons. "n=76" } & \multirow{2}{*}{ p-value } \\
\hline & No. & $\%$ & No. & $\%$ & \\
\hline $\begin{array}{c}\text { 1-Age "years" } \\
\text { 18-29yrs. } \\
\text { 30-39yrs. } \\
\text { 40-49yrs. }\end{array}$ & $\begin{array}{l}10 \\
6 \\
6\end{array}$ & $\begin{array}{l}41.67 \\
23.07 \\
23.07\end{array}$ & $\begin{array}{l}2 \\
13 \\
26\end{array}$ & $\begin{array}{l}2.63 \\
17.10 \\
34.21\end{array}$ & $\mathrm{P}<0.02 *$ \\
\hline
\end{tabular}


Minia Scientific Nursing Journal (Print - ISSN 2537-012X) (Online - ISSN 2785-9797) Vol. (9) No. (1) June 2021

\begin{tabular}{|c|c|c|c|c|c|}
\hline \multirow{2}{*}{ Item } & \multicolumn{2}{|c|}{$<6$ mons." } & \multicolumn{2}{|c|}{$>6$ mons. "n=76" } & \multirow{2}{*}{ p-value } \\
\hline & No. & $\%$ & No. & $\%$ & \\
\hline 50-65yrs. & 2 & 8.33 & 35 & 46.05 & \\
\hline $\begin{array}{l}\text { 2-Residence: } \\
\text { Urban } \\
\text { Rural }\end{array}$ & $\begin{array}{l}6 \\
18\end{array}$ & $\begin{array}{l}25.0 \\
75.0\end{array}$ & $\begin{array}{l}27 \\
49\end{array}$ & $\begin{array}{l}35.52 \\
64.47\end{array}$ & $\mathrm{P}<0.03 *$ \\
\hline $\begin{array}{l}\text { 3-Marital status: } \\
\text { Single } \\
\text { Married } \\
\text { /widowed/divorced }\end{array}$ & $\begin{array}{l}5 \\
19\end{array}$ & $\begin{array}{l}20.83 \\
79.17\end{array}$ & $\begin{array}{l}14 \\
62\end{array}$ & $\begin{array}{l}18.42 \\
81.57\end{array}$ & $\mathrm{P}=0.241 \mathrm{n} . \mathrm{s}$ \\
\hline $\begin{array}{l}\text { 4-Occupation: } \\
\text { Student } \\
\text { Employed } \\
\text { House wife }\end{array}$ & $\begin{array}{l}2 \\
16 \\
6 \\
\end{array}$ & $\begin{array}{l}8.33 \\
66.67 \\
25.0 \\
\end{array}$ & $\begin{array}{l}5 \\
9 \\
6\end{array}$ & $\begin{array}{l}6.75 \% \\
11.84 \% \\
81.57 \%\end{array}$ & $\mathrm{P}<0.000 * * *$ \\
\hline $\begin{array}{l}\text { 5-Level of education: } \\
\text { Illiterate } \\
\text { Primary } \\
\text { Secondary } \\
\text { Higher educational } \\
\end{array}$ & $\begin{array}{l}0 \\
9 \\
8 \\
7 \\
\end{array}$ & $\begin{array}{l}0 \\
37.5 \\
33.33 \\
29.16 \\
\end{array}$ & $\begin{array}{l}70 \\
3 \\
2 \\
1 \\
\end{array}$ & $\begin{array}{l}92.10 \% \\
3.94 \% \\
2.63 \% \\
1.31 \% \\
\end{array}$ & $\mathrm{P}<0.000 * * *$ \\
\hline $\begin{array}{l}\text { 6-Monthly income: } \\
\text { Low } \\
\text { High }\end{array}$ & $\begin{array}{l}7 \\
19\end{array}$ & $\begin{array}{l}29.1 \\
79.16\end{array}$ & $\begin{array}{l}50 \\
33\end{array}$ & $\begin{array}{l}65.78 \\
43.42\end{array}$ & $\mathrm{P}<0.001 * *$ \\
\hline
\end{tabular}

Table (4) explained that there was a high significance difference $(\mathrm{P}<0.000)$ between the level of education with delay diagnosis, also there was a high significance difference $(\mathrm{P}<0.000)$ between time delayed to diagnosed with occupation .

Table (5): Percentage distribution of study sample according to Correlation between delay time of diagnosis and grading of tumors.

\begin{tabular}{|c|c|c|c|c|c|c|}
\hline \multirow[t]{2}{*}{ Item } & \multicolumn{2}{|l|}{ T size } & \multicolumn{2}{|c|}{ N lymph node } & \multicolumn{2}{|c|}{ Metastases } \\
\hline & $\mathbf{R}$ & $\mathbf{P}$ & $\mathbf{R}$ & p & $\mathbf{r}$ & p \\
\hline 1-Time of appearance of symptoms & 0.375 & $<0.03 *$ & 0.461 & $<0.001^{*}$ & 0.018 & $\mathrm{P}=0.24 \mathrm{n} . \mathrm{s}$ \\
\hline 2-Time of the first consultation & 0.432 & $<0.02 *$ & 0.268 & $<0.001 * *$ & 0.072 & $\mathrm{P}<0.02 *$ \\
\hline 3-Time of first diagnosis $\&$ treatment & 0.238 & $<0.001 * *$ & 0.418 & $<0.001 * *$ & 0.431 & $\mathrm{P}<0.001 * *$ \\
\hline 4-Delay treatment "months" & 0.437 & $<0.000^{* * *}$ & 0.237 & $<0.001 * *$ & 0.438 & $\mathrm{P}<0.001 * *$ \\
\hline
\end{tabular}

$\mathrm{R}(\mathrm{p}): \mathrm{r}$ : correlation coefficient $\quad \mathrm{P}: \mathrm{p}$-value

Table (5) explicated that there was a positive correlation increasing between each of size of the tumor, N lymph node and metastases with increase delayed time of diagnosis.

\section{Discussion}

Delay diagnosis of breast cancer is more responsible rather than the disease itself in causing high incidence and mortality rates, leaving a large low of survival with significant impact on the individuals residual physical and psychological impairments (Fitzmaurice.,et al,2019).

The finding of the current study revealed that the youngest and oldest patients aged 18 and 65 years old with mean age 46.23 year and more than one third of women less than 40 years, this result agrees with M.Shreyamsa, et al, (2020) who reported that in a cohort study that about more than one third of patients were below the age of 40 years, occurrence of breast cancer in young age is unique biologically with gene expression and gene mutation that is different from the older patients, on other hand the result of current study contradicted with Bariati et al, (2017) .

In my point of view and supported by Dianatinasab et al (2016) who stated that younger women had greater delay on account of the breast density decreases with age and therefore mammography became better in sensitivity and thus physicians give greater priorities and to attention old-aged and adults women than youngsters.

Concerning to educational level, the present study findings demonstrated that two- third of breast cancer patients were illiterate. In my point of view which supported by Bray, et al (2018), illiteracy formed important contributing factor for delayed diagnosis of breast cancer because of lack of knowledge and awareness about breast cancer disease, this result supported by (Rivera-Franco, et al., 2018) who reported that illiteracy is a social barrier and main cause for late diagnosis of breast cancer, in contrast, Jignasa ,et al (2017) found that patients with breast cancer are significantly more educated, education does not mean that people will follow all the health guidelines .

The result of the present study illustrated that, twothird of breast cancer patients were from the rural area. In my point of view and similar to Grosse, et al (2018) the longer delay among rural female patients might be due to low awareness level and lack of direct approach to cancer centers for rural residents. They additionally need to venture out significant distances to approach medical facilities. Rural culture and social values likewise restrict women from consulting their disease with others and also it could lead to negligence, ignorance, this finding is compatible with Dianatinasab, et al., (2018)

The result of current study showed that half of patients were married, this agreement with (Nene, et al., 2018) who reported that married women had longer patient delay compared with single patients in seeking health cares and this due to women financially and culturally dependent on husbands, may fear of divorce and remarriage of the husband .

The findings of the present study showed that twothird of the patients was housewives and this similar to Majeed et al (2020) who stated that unemployed women faced longer delay in comparison with employed women who had shorter delay. On other hand, this result was contrdicted with Amornsak et al (2014) who reported that employed women had more delay than unemployed women.

The result of current study demonstrated that more than half of patients had low income, this result similarly to 
Mohaghegh et al(2015) who also reported low economic status is one of the risk factors of late diagnosis of breast cancer.

The present study results founded that the total time delay was 15.43 months and this result compatible with a study done in Sub-Saharan African nations by Odongo et al,(2015) which showed that the presentation delay was even higher around 13 months .In contrary to the current study finding Rivera-Franco and Leon-Rodriguez, (2018) mentioned that the median delay to the first consultation was 9-61 days.

The current research illustrated that the majority of study sample had lack awareness and knowledge about breast cancer and its signs \&symptoms, this result supported Kitano , et al(2018) who stated that the most of women had lack of awareness and knowledge related to breast cancer which leads to diagnosis at later stages and consequently to lower survival rates.

In my point of view, Lack knowledge about breast cancer disease, its manifestations, and screening test linked with illiteracy and these causes supported by Akuoko, et al (2017).

The result of the study illustrated that the half of patients had fear of disease \& treatment adverse effects. In my point of view, fear is an unpleasant feeling caused by the threat of pain, danger, women respond to this fear by denying the disease because of negative information about breast cancer and its therapy, for example, fear from radiotherapy, the toxicity of chemotherapy, and side effect which can result in refusal of therapy, fear of remarriage of the husband or divorce could lead some women to choose not to seek diagnosis even if they suspected having breast cancer and this explanation about women fear supported by Cynthia, et al (2017).

The result of current study supported by Oatraso, et al., (2015). On other hand the finding of this study contrast with Ermiah, et al (2012) who stated that minimum percent of patients with $\mathrm{BC}$ considered fear to be a reason for late presentation or delayed diagnosis.

According to the relationship between sociodemographic characteristics and delay diagnosis, the finding of the present study revealed that there was a highly significance difference $(\mathrm{P}<0.000)$ between level of education with delay diagnosis this finding agrees with Jassem et al,(2014), there was a highly significance difference between unemployed women and long delay and this supported by Doyle K, et al ,(2019) who stated that actively unemployed women showed long delay compared with employed women.

In contrast Arvind et al, (2019) who reported that no significant association between socio demographic characteristics and long diagnosis delay expect level of education.

According to the correlation between delay time of diagnosis and grading of tumors in the study sample, the result of the current study showed that there was a positive correlation increasing between each of size of the tumor, $\mathrm{N}$ lymph node and metastases with longer delay and this result agreement with Jassem et al,(2014) who stated that longer delay associated with larger tumor size, affected lymph node and metastases.

\section{Conclusion:}

Overall, patient delays were the most significant reasons for delayed diagnosis of breast cancer in our study.
Our results showed that higher educational level and monthly income were associated with shorter patients' delay. Furthermore, lack of knowledge and awareness about breast cancer disease and fear are the most reason for delay. Our results can be used to implement strategies to shorten both patients' delay and system delay in diagnosis of breast cancer to prevent disease progression and decrease mortality rate in patients.

\section{Recommendations:}

Educational program is needed to increase females' awareness and knowledge about disease and screening test of early detection. Health education and teaching for general practitioners especially for nurses to increase their awareness about important of early detection and screening test of breast cancer.

\section{References}

(1) Ahmed,A., May, A., Amrou ,M., Sali ,K., Ahmad, M., . Breast Cancer Awareness among Egyptian Women and the Impact of Caring for Patients with Breast Cancer on Family Caregivers' Knowledge and Behaviour. Research in Oncology 2020; Vol. X, No. X: X-X. DOI: 10.21608/resoncol.2020.42340.1114.

(2) Akuoko CP, Armah E, Sarpong T, et al. Barriers to early presentation and diagnosis breast cancer among African women living in sub-Saharan Africa. PLoS One. 2017; 12(2):e0171024.

(3) Amornsak P., Supannee, P., Stephen ,W ., Donald ,M.Factors Associated With Delayed Diagnosis of Breast Cancer in Northeast Thailand .J Epidemiol.2014; 24(2):102-108.

(4) Arvind, K.,Srabana, M., Jaya ,P.,et al.,. Delays in Diagnosis and Treatment of Breast Cancer and the Pathways of Care: A Mixed Methods Study from a Tertiary Cancer Centre in North East India, Asian Pacific Journal of Cancer Prevention,(2019). Vol 20 (12), 3711-3721.

(5) Bairati I, Jobin E, Fillion L, Larochelle M, Vincent L. Determinants of delay for breast cancer diagnosis. Cancer Detect Prev 2017;31(4):323-31.

(6) Bray F, Ferlay J, Soerjomataram I, Siegel RL, Torre LA, Jemal A . Global cancer statistics (2018): GLOBOCAN estimates of incidence and mortality worldwide for 36 cancers in 185 countries. CA Cancer J Clin.

(7) Caplan L . Delay in breast cancer: implications for stage atdiagnosis and survival. Front Public Health (2014)2:87 .

(8) Cynthia, P., Ernestina, A., Theresa, S., Dan ,Y.,Isaac ,A., Daniel, B., (2017).Barriers to early presentation and diagnosis of breast cancer among African women living in sub-Saharan Africa DOI:10.1371/journal.pone.0171024 February 13.

(9) Dianatinasab M, Fararouei M, Mohammadianpanah M, ZareBandamiri M . Impact of social and clinical factors on diagnostic delay of breast cancer-a cross-sectional study. Medicine (2016).95: 38(e4704).

(10) Doyle K, Newman RM, Sullivan M, Pergolotti M, Braverman B, Cheville AL. Employment concerns and associated impairments of women living with advanced breast cancer, Arch Rehabil Res Clin Translation. June;(2019).1(1-2):100004.

(11) Ermiah E, Abdalla F, Buhmeida A, et al: Diagnosis delay in Libyan female breast cancer. BMC Res Notes 5:452, 2012.

(12) Fitzmaurice C, Abate D, Abbasi N, et al. Global, regional, and national cancer incidence, mortality, years of life lost, years lived with disability, and disability-adjusted lifeyears for 29 cancer groups, 1990 to 2017: A systematic 
analysis for the Global Burden of Disease Study. JAMA Oncol. (2019); 5(12): 1749- 1768.

(13) Gehan M. Ismail, Azza A. Abd El Hamid and Amel G. Abd ElNaby. Assessment of Factors that Hinder Early Detection of Breast Cancer among Females at Cairo University Hospital. World Applied Sciences Journal 23 (1): 99-108, 2013.

(14) Grosse Frie K, Kamaté B, Traore CB, Ly M, Malle B, Coulibaly B, et al., Factors associated with time to first healthcare visit, diagnosis and treatment, and their impact on survival among breast cancer patients in Mali. PLoS One.; (2018)13(11):e0207928.

(15) Jassem J, Ozmen V, Bacanu F, Drobniene M, Eglitis J, Lakshmaiah KC, et al. Delays in diagnosis and treatment of breast cancer: a multinational analysis. Eur J Public Health. 2014; 24:761-7. DOI: 10.1093/eurpub/ckt131.

(16) Jignasa ,Amrutlal .Ganesh ,B.Saurabh ,C. Aanchal, J. Sushama, S.Sociodemographic Factors and Late-stage Diagnosis of Breast Cancer in India: A Hospital-based Study. Indian Journal of Medical and Paediatric Oncology | Published by Wolters Kluwer - Medknow.

(17) Kantelhardt EJ, Muluken G, Sefonias G, Wondimu A, Gebert HC, Unverzagt S, Addissie A: A review on breast cancer care in Africa. Breast Care 2015;10:364-370.

(18) Kitano A, Shimizu C, Yamauchi H, Akitani F, Shiota K, Miyoshi Y, et al. Factors associated with treatment delay in women with primary breast cancer who were referred to reproductive specialists. ESMO Open. 2019 Mar 5;4(2):e000459.

(19) M. Shreyamsa1 \& Devina Singh2 \& Pooja Ramakant1 \& Akshay Anand3 \& Kul Ranjan Singh1 \& Sasi Mouli1 \& Anand Kumar Mishra1 \& A. A. Sonkar3 Barriers to Timely Diagnosis and Management of Breast Cancer: Observations from a Tertiary Referral Center in Resource Poor Setting. Indian Journal of Surgical Oncology (June 2020) 11(2):287-293.

(20) Maghous,A., Rais, F., Ahid, S., et al., Factors influencing diagnosis delay of advanced breast cancer in Moroccan women. Research article: BMC cancer.(2016)vol(16):356:DOI 10.1186/s12885-016-2394y.
(21) Majeed I; Ammanuallah R; Anwar AW; Rafique HM; Imran F. Diagnostic and treatment delays in breast cancer in association with multiple factors in Pakistan. East Mediterrn Health J.(2020);26(x):xxx-xxx.

(22) Mc Cutchan GM, Wood F, Edwards A, Richards R, Brain KE. Influences of cancer symptom knowledge, beliefs and barriers on cancer symptom presentation in relation to socioeconomic deprivation: a systematic review. BMC cancer. (2015);15:1000.

(23) Mohaghegh P, Yavari P, Akbari ME, Ahmadi F. Associations of demographic and socioeconomic factors with stage at diagnosis of breast cancer. Asian Pac J Cancer Prev. (2015);16(4):1627-31.

(24) Nene BM, Selmouni F, Lokhande M, Hingmire SJ, Muwonge R, Jayant K, Sankaranarayanan R . Patterns of care of breast cancer patients in a rural cancer center in Western India. Indian J Surg Oncol (2018).9:374-380.

(25) O atraso de paciente e atraso de sistema no tratamento do câncer de mama nos países desenvolvidos e em desenvolvimento. Patient delays and system delays in breast cancer treatment in developed and developing countries. Ciência \& Saúde Coletiva (2020)Print version ISSN 1413-8123On-line version ISSN 1678-4561.

(26) Odongo J, Makumbi T, Kalungi S, Galukande M. Patient delay factors in women presenting with breast cancer in a low income country. BMC Res Notes. (2015);8:467.

(27) Rivera-Franco MM, Leon-Rodriguez E. Delays in breast cancer detection and treatment in developing countries. Breast Cancer (Auckl) (2018)12:1178223417752677.

(28) Salwa, H., Dorria, S., Hoda, Z., Suzan, A. nurse's role in early detection of breast cancer through mammography and genetic screening and its impact on patient's outcome .International Journal of Medical, Health, Biomedical, Bioengineering and Pharmaceutical Engineering (2015)Vol:9, No:2, 162-155.

(29) Stiefel F: Understanding why women delay in seeking help for breast cancer symptoms. J Psychosom Res (2016);60:309-310.

(30) World Health Organization, Women and health: today's evidence, tomorrow's agenda. World Health Organization, 2020. 